\title{
Chapter 4 \\ Case Study of Alternative Jet Fuel Production with Bio-additives from Plant Oils in Ukraine and Poland
}

\author{
Anna Yakovlieva, Sergii Boichenko, Oksana Vovk, Kazimierz Lejda, \\ and Oleksandr Gryshchenko
}

\subsection{Introduction}

One of the features of the modern world is the increased attention of the international community to the problems of rational and efficient use of energy resources, introduction of energy-saving technologies, and searching of renewable energy.

Today, renewable energy development in the world took an accelerated character that is associated with the growing of global multifactorial crisis phenomena. On the one hand, there is limitation of geological reserves of the main types of fuel resources - oil and gas - which leads to an inevitable rise in prices for them. On the other hand, there is the obvious growth of the negative environmental impacts, which are caused by the effects of human activity.

Today application of alternative energy sources in various spheres of human activity becomes more and more popular all over the world and in Eastern European countries as well. Along with the development and implementation of alternative motor fuels, scientists around the world study perspectives of partial or total substitution of traditional jet fuels with their alternative analogues. Following the world tendencies, we see the need to consider the potential in development and application of alternative jet fuels produced from plant oils. The analysis was done for Eastern Europe countries, such as Ukraine and Poland.

A. Yakovlieva $(\square) \bullet \mathrm{S}$. Boichenko $\bullet$ O. Vovk $\bullet$ O. Gryshchenko National Aviation University, Kyiv, Ukraine

e-mail: pinchhuk_anya@ukr.net

K. Lejda

Rzeszow University of Technology, Rzeszow, Poland 


\subsection{Literature Overview}

Modern civil aviation is developing constantly. The world volume of aircraft transportation increases 4-5\% annually. As a result during the last decade, consumption of fuels for air-jet engines has increased to $21 \%$. As it is stated in [7], about 5.5 thousand barrels of jet fuel are produced and consumed in the world daily. Dynamics of jet fuel consumption in Ukraine and Poland are shown in Fig. 4.1.

Thus, today aviation is one of the most significant consumers of oil-derived jet fuels. Oil and other fossil fuels used for production of both jet and other kinds of fuels are exhausted irreversible. Oil deposits are estimated to last for 40 years, natural gas for 70 years, and coal for 230 years. $\mathrm{CO}_{2}$ emissions accompanying processes of fuel production and use stipulate the increase of greenhouse effect and therefore global warming [6]. The Intergovernmental Panel on Climate Change and International Energy Agency (IEA) state that modern aviation is a source of about $2 \%$ of the world's total $\mathrm{CO}_{2}$ emissions (Fig. 4.2).

Such rapid increase of $\mathrm{CO}_{2}$ in the atmosphere is connected to active development of the aviation industry. According to the forecasts, the number of aircrafts will increase two times till 2031 and will total to about 31 thousand units. Enlargement of air fleet and number of flights consequently leads to increasing jet fuel consumption. During the 10-year period (1992-2002), the level of jet fuel consumption has risen by $21 \%$. Besides $\mathrm{CO}_{2}$ aircraft exhaust gasses contain a number of other components that negatively influence the state of the environment: $\mathrm{SO}_{\mathrm{x}}, \mathrm{NO}_{\mathrm{x}}, \mathrm{CO}, \mathrm{CH}_{4}$, soot, and others [7].

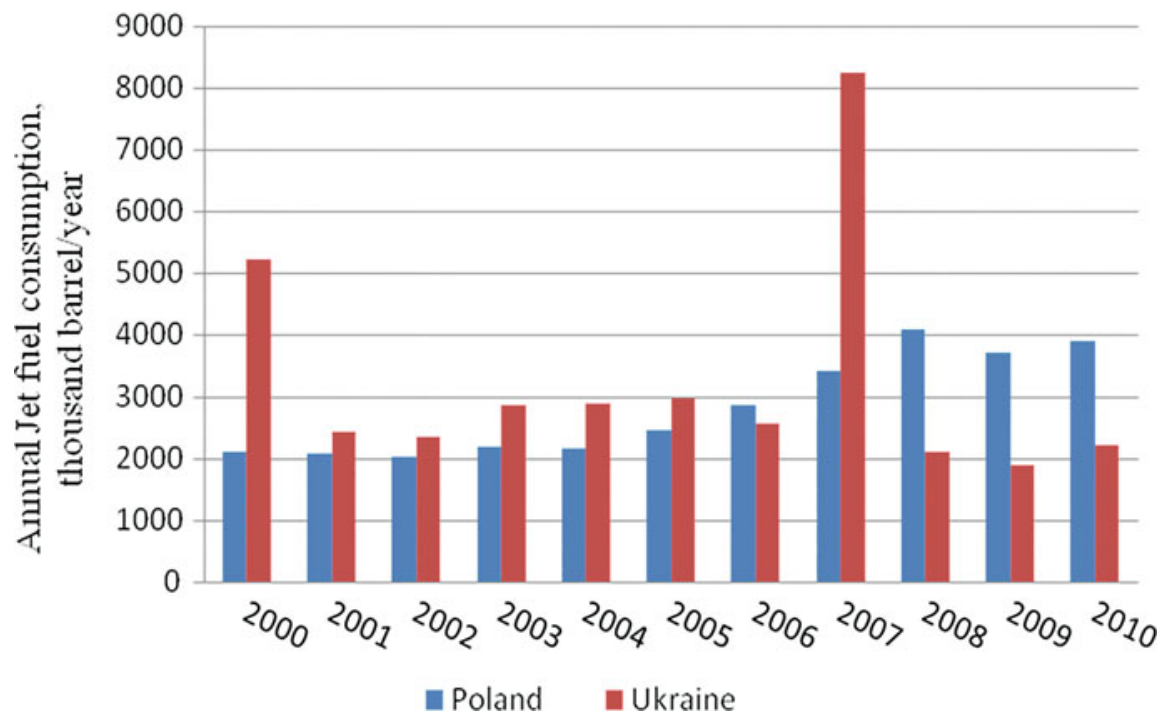

Fig. 4.1 Statistics of jet fuel consumption in Poland and Ukraine 


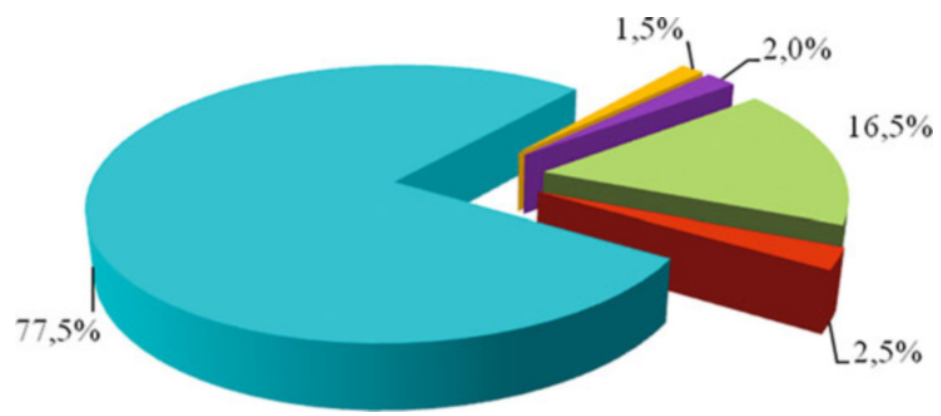

Fig. 4.2 The share of $\mathrm{CO}_{2}$ emissions from air transport compared to other kinds of transport: $1.5 \%$, international aviation; $2 \%$, international marine transport; $16.5 \%$, motor transport; $2.5 \%$, other kinds of transport; $77.5 \%$, other energy sources

Quantitative and qualitative composition of aircraft emissions determines ecological properties of jet fuels. Mostly they depend on the content of heteroatom compounds and aromatics in fuel. In other words, ecological properties of jet fuels and aircraft's emissions are determined by the quality of crude oil [2]. We should mention that the amount of greenhouse gas formation during jet fuel production from natural gas is 1.8 times lower and from coal is 2.4 times higher compared to crude oil. Processing of bituminous coal is accompanied with $\mathrm{CH}_{4}$ emission that is also one of the greenhouse gasses. At the same time $\mathrm{SO}_{\mathrm{x}}$ emissions are absent during the combustion of fuel made of natural gas [2].

The main environmental damage associated with global climate change of the Earth is greenhouse effect, caused mainly from mining, processing, and burning of fossil fuels - coal, oil, and gas. The greenhouse effect is up to $75 \%$ share of the anthropogenic environmental damage. In this regard, the satisfaction of growing needs of the world's population in fuel, electricity, and heat simultaneously with the environmental safety necessitates the development of renewable energy, because oil is not single raw material for getting of high-efficient organic fuels for engine.

In terms of global pollution, air transport is responsible for direct and indirect emissions of several greenhouse gasses: $\mathrm{CO}_{2}(2 \%$ of global emissions by IATA International Air Transport Agency), tropospheric ozone, methane, etc. [2]. More than once the Committee on Environment Impact of Aviation (CAEP) raised the issue of reducing emissions including emissions of $\mathrm{NO}_{\mathrm{x}}$ and $\mathrm{CO}_{2}$. With the support of ICAO, the strategic document of the 38th Assembly of ICAO has presented strategic plans in the field of environmental protection regarding emissions of aircraft engines that affect local air quality, the impact of international aviation, and climate change, including the progress on the part of new aviation standards on emissions of $\mathrm{CO}_{2}$, plans of action of countries and ASSIST countries, environmental alternative fuels for the aviation, market activities, and global goals [9, 22].

The initiator of the development and implementation of alternative (including biological) fuels for aviation is the International Civil Aviation Organization (ICAO). Back in 1983, the ICAO established the structure of the technical com- 
mittee on environmental protection in aviation (CAEP), which is the active target group (subcommittee) on alternative fuel (AFTF). The AFTF is concerned with the economic feasibility of aviation biofuels, determined mainly by two criteria:

- The need to improve fuel efficiency in aviation because of the well-known global problem of depletion of hydrocarbon fuels derived from petroleum.

- The need to reduce emissions of harmful substances in the exhaust gas of gas turbine engines, that is, an increase in environmental performance of aviation fuel. This criterion is now the dominant and determining the actions of scientists and practitioners.

Following 6 years of negotiations, governments meeting at the International Civil Aviation Organization (ICAO) are finalizing the design elements of a global marketbased measure for international aviation. It is part of a series of actions the aviation industry is taking to reduce its carbon emissions which includes investing in new technology, scaling up the use of sustainable alternative fuels, improving operational performance of aircraft already in the fleet, and using more efficient infrastructure.

The carbon offsetting and reduction scheme for international aviation (CORSIA) has been agreed by government negotiators at the 39th ICAO Assembly. The CORSIA will be the world's first market mechanism for dealing with climate change from any industrial sector. The global aviation industry, coordinated by the Air Transport Action Group (ATAG), has been instrumental in proposing the plan and is now encouraging states to support it.

Such a situation promoted strengthening of ecological requirements of quality of jet fuels. A number of influential organizations took measures on the prevention of negative impacts of aviation on the environment [1]. The International Air Transport Association (IATA) has set up the task to reduce the level of $\mathrm{CO}_{2}$ emissions from air transport by $50 \%$ by 2050. In addition, the European Commission in 2011 has set a policy target of achieving a $60 \%$ reduction of $\mathrm{CO}_{2}$ by 2050 . Low-carbon fuels in aviation should reach $40 \%$ by 2050 . Besides, the European Committee insists on using about $4 \%$ of fuel produced from plant feedstock in aviation. In the future this may help to step forward in achieving the goal to cut down $\mathrm{CO}_{2}$ emissions. According to the experts' forecast, the use of jet biofuels can guarantee an $80 \%$ reduction of $\mathrm{CO}_{2}$ emissions compared to conventional jet fuel [3].

Thus, we can see that the search in methods and technologies of alternative jet fuel production from renewable feedstocks was acknowledged as a key direction for solving such questions about energy and resource saving and environmental protection in aviation.

\subsection{Modern Situation in Sphere of Jet Fuel Production}

Traditionally fuels for jet engines are produced from crude oil, coal, natural gas, oil sands, and oil shales. However, technologies are quite energy intensive and difficult to realize. The limitation of the world's oil deposits and other fossil fuels promotes the development of alternative technologies for jet fuel production. Today 
numbers of organizations pay much attention to the investigation of existing and newly appeared technologies for alternative jet fuel production. Scientists define jet fuels derived from conventional oil, unconventional oil (oil sands and oil shale), natural gas, coal, or biomass via the FT process, renewable oils (biodiesel, biokerosene, hydroprocessed renewable jet or hydrotreated vegetable oil - HVO), and alcohols (ethanol and butanol). However, alcohol-derived fuels are suitable for aviation piston engines only [6]. The most perspective are fuels derived from plant feedstock - the so-called biofuels. IEA forecasts that the share of biofuels in the total balance of fuel in the transport sector will reach 4-6\% till 2030.

The development and use of jet biofuels contribute to the appropriate legal regulation. Implementation guidelines strictly define certain types of biofuels in the consumer market. Today areas used for biofuel crop cultivation in Europe are more than 2500 ha. Basically these crops are cereals and rape seed. At present, the 13.2 ha of EU lands are available for cultivation of biofuel cultures. Till 2020 this area may increase up to 20.5 ha and till 2030 to 26.2 ha. According to the European Commission, in order to achieve the 2020 goal for energy crops, it is necessary to use 17.5 ha or about $10 \%$ of agricultural lands used in the EU countries.

Biofuel holds a special place in the structure of renewable energy sources. Being one of the few alternative fuels in the transport sector, biofuels are seen as an important resource in the choice of energy sources, in ensuring energy security, in the development of agriculture and rural areas, as well as in the mitigation of climate change by reducing greenhouse gas emissions.

The formal classification of energy crops to the appropriate categories (Fig. 4.3) has been published in a report titled Biofuels in the European Vision, Vision 2030 and Beyond. According to these reports, biofuels are divided into the first- and second-generation biofuel. The Department of Transport and Energy of the European Commission has figured out a third-generation biofuel. The third-generation fuel, known as a future fuel, may be obtained from oils produced from micro- and macroalgae.
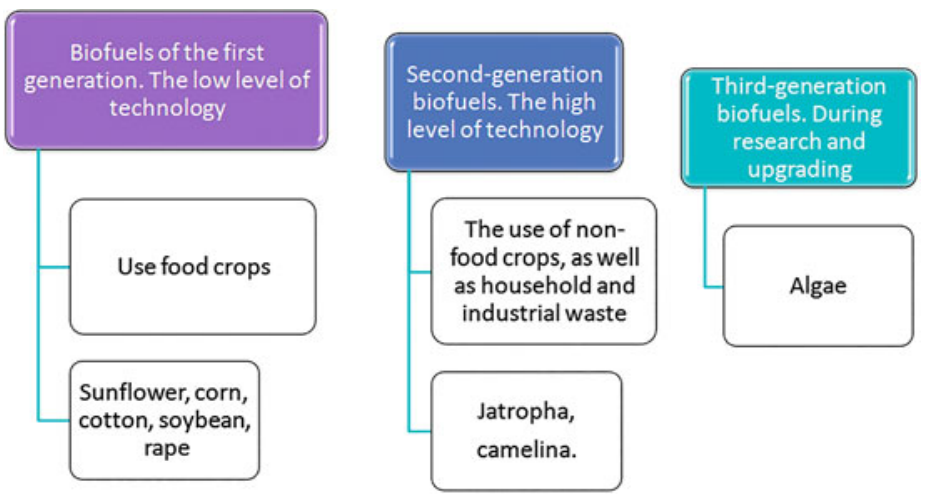

Fig. 4.3 Classification of biofuels according to generations 
Conditionally biomass as feedstock for biofuel production can be divided into three generations. The following are the current generations of biofuels:

- Edible oil and sacchariferous terrestrial plants

- Inedible cellulosic plants

- Inedible aquatic plants, i.e., algae

First-generation biofuel is made from sugar, starch, vegetable oil, and animal fat using conventional technology. The main sources of raw materials are the seeds or grains, for example, from rapeseed extract vegetable oil, which can then be used as biodiesel, and from wheat-obtained starch, after fermentation - bioethanol.

Deforestation, negative impacts on traditional agriculture, the imbalance of agricultural land use in the direction of industrial crops, and the threat of the food security are some of the problems humanity is facing during the production of biofuels. The main problem in the production of fuel from biomass is food security, because first-generation biofuels made from agricultural crops enter the food chain of humans and animals (corn, soybeans, palm oil, rape, sugarcane, wheat, rye). The public has thought suddenly that large areas where food was produced by commercially oriented farmers was given to the technical culture. Because the world population grows and requires more and more food, the use of these areas for the production of biofuels reduces the amount of available food and increases their prime cost.

Second-generation biofuels are produced from non-food raw materials. Sources of raw materials are lignocellulosic compounds the remaining after, as suitable for use in the food industry part of vegetable raw materials are removed. For this purpose, fast-growing trees and grasses (poplar, willow, Miscanthus, Jatropha, etc.) can also be used. They are also called energy forests or plantations. Twenty different species of plants, including arboreal, shrubs, and herbaceous, are tested.

In September 2013, the European Parliament decided to reduce the share of firstgeneration biofuels in total biofuel balance because of its environmental load. It is easy to consider, when the yield of a crop like rape is $30 \mathrm{~kg} / \mathrm{ha}$, then it is possible to obtain 1.0-1.3 tons of oil per hectare. It means that about nine million hectares of arable land was used for cultivation of technical culture. At the same time 45$80 \mathrm{~kg}$ of nitrogen, $18-40 \mathrm{~kg}$ of phosphorus, $25-100 \mathrm{~kg}$ of potassium, $30-150 \mathrm{~kg}$ of calcium, 5-15 kg of magnesium, and $30-45 \mathrm{~kg}$ of sulfur were taken out from the soil during the production 1 ton of seeds. So, we can easily conclude that the production of biofuel crops depletes the fertile layer of soil of $2 \mathrm{~cm}$ thick that was formed over 100 years. The production of renewable raw materials for biofuels without scientific justification leads to the depletion of the soil and reduction of crop yields, deterioration of raw material for biofuel, and water and soil pollution by agrochemicals and fertilizers.

During the last years, we observe criticism of first-generation biofuels because the fuel produced from rapeseed and similar crops is not effective for reducing $\mathrm{CO}_{2}$ emissions. The proportion of first-generation biofuels in transport fuel balance according to the decision of the European Parliament should be reduced to 5.5\%. In addition, after 2020, the EU may completely abandon the first-generation biofuels. 
This fact stimulates the search for new, cost-effective technologies, which will use the second-generation feedstock, which resources are almost unlimited. These sources should be crops of non-food purposes, perennial grasses, and agricultural waste of food and forestry industries. The main advantages of the second-generation biofuels compared to the first generation are the following:

- Variety of biomass, suitable for processing.

- Higher efficiency - on average by $30-40 \%$.

- Reduction of greenhouse gas emissions in case of applying second-generation biofuels can reach up to $90 \%$ (first-generation biofuel - 50\%).

If we talk about the state of biofuel production in Ukraine, we should conclude that the level of biofuel branch development is significantly lower than in EU countries. According to [11] the total supply of primary energy sources in Ukraine is more than $130 \mathrm{M}$ ton of oil equivalent, but the amount of biofuel is just $1.48 \mathrm{M}$ ton, that is, $1.13 \%$ in structure of energy supply. At the same time in EU countries, this index reaches $6.72 \%$. The total supply of primary energy in EU countries is estimated at $1759 \mathrm{M}$ ton of oil equivalent with the share of biofuels of $118 \mathrm{M}$ ton (Fig. 4.4a-c) [12].

It should be stated that the existing potential of Ukraine in the production of biofuels is not used completely, even concerning the first-generation biofuels. This is due to the lack of modern plants for its production. Transition to the use of the second-generation feedstock is possible only through the development of modern industry for the processing of raw materials of the first generation, which can create the technological basis for a gradual use of the second-generation feedstock, as well as the expansion of the resource base by selection of alternative crops, making them productive varieties and their implementation into production.

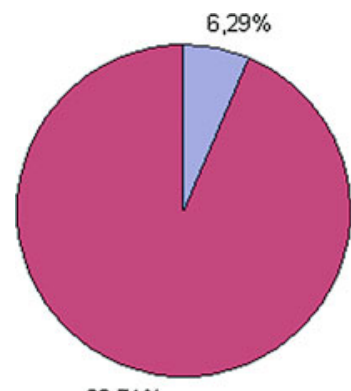

$93,71 \%$

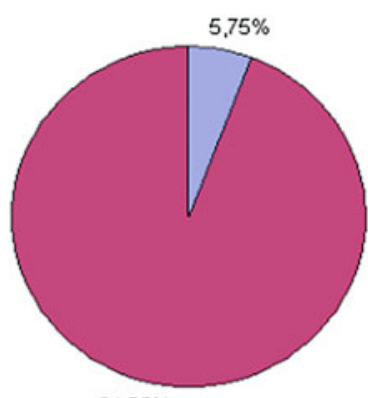

$94,25 \%$

a

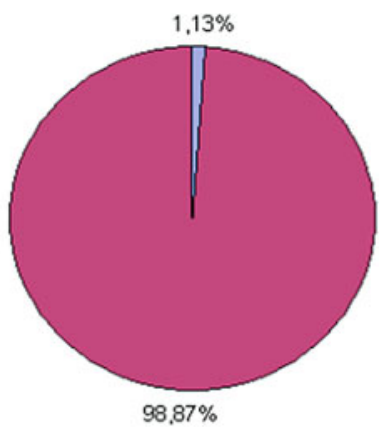

c

$\square$ Traditional energy sources $\quad$ Biofuels

Fig. 4.4 Share of biofuels in structure of energy supply (a) in EU countries, (b) in Poland, (c) in Ukraine 


\subsection{State and Perspectives of Jet Biofuel Production in Ukraine and Poland}

Poland and Ukraine as well as other European states are characterized by the deficiency of oil deposits. Ukraine consumes about $130 \mathrm{M}$ ton of fuel-energy resources annually, satisfying its need in energy resources on around 53\%. In order to satisfy needs of civil aviation, Ukraine requires about 400,000 ton of aviation kerosene. At the same time, sphere of jet fuel production is characterized by the opposite situation. The production of aviation kerosene at Ukrainian enterprises in 2011 decreased at $16.6 \%$ compared to the previous year up to 282,000 ton. The final energy consumption for transportation purposes in Poland in 2005 was 10.27 million ton of energy equivalent (Mtoe).

Generalizing the world's experience in alternative jet fuel development, we have concluded that the most optimal kind of aviation biofuels is biokerosene, which is derived from renewable oils [8]. The technology of biokerosene manufacturing seemed to be the most rational for both Ukrainian and Polish conditions. This kind of biofuel is obtained via processing of oil plants. Biokerosene is a mixture of traditional kerosene, produced from crude oil and biocomponents in certain concentrations. The percentage of biocomponent can reach 50\%. Advantages are explained by the availability of feedstock, maturity of technology, presence of necessary equipment, satisfactory physical-chemical and exploitation properties of such kinds of biofuel, and also its ecological safety.

\subsubsection{Feedstock Base for Jet Biofuel Production}

The feedstock for biocomponent production is oils, obtained from seeds of various agricultural oily plants: rape, sunflower, camellina, Jatropha, canola, palm oil, etc. The main factor for feedstock selection is surely geographical and climatic conditions typical for country-producer and optimal for certain oily plant cultivation [3]. The base of European biofuel industry is rape and during the last years camelina. Ukraine and Poland are traditionally agricultural countries with well-developed oil production branch $[17,18]$. Due to this they have a great potential for the development of jet biofuel manufacturing. The most typical oil cultures in Ukraine are sunflower, rape, and soy; camelina and corn are less popular (Fig. 4.5).

During 1990-2011 cultivating areas under oily plants in Ukraine had increased 3.7 times (Fig. 4.6). Such strong development of the industry was explained by stably high profitability of cultures, annually growing demand for feedstock in food industry, animal farming, and biofuel industry.

Due to the large area of agricultural terrains, Poland has a great potential to use renewable energy. The main renewable energy source in Poland is biomass. Today Poland is one of the most promising countries in EU concerning biofuel feedstock production. The most typical oil cultures in Poland are sunflower and rape (Fig. 4.7) [17]. 


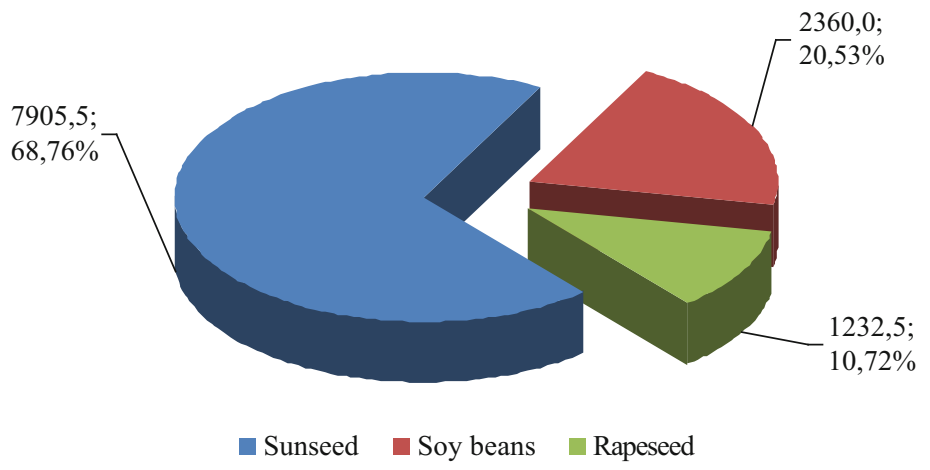

Fig. 4.5 Production of main oily plants in Ukraine in 2012 (thousand ton)

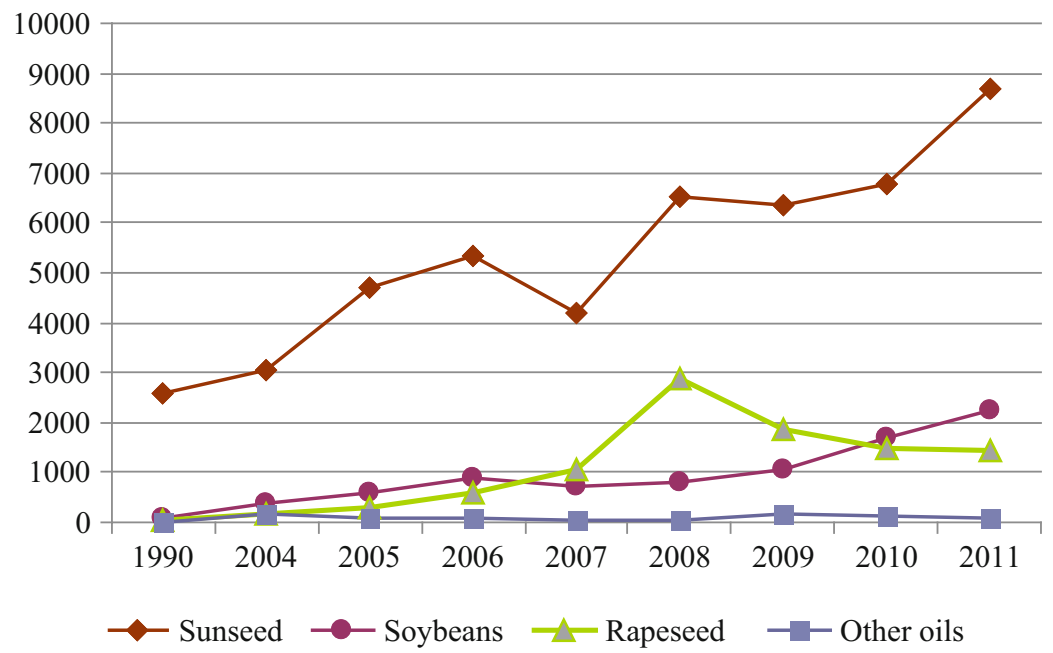

Fig. 4.6 Dynamics of main oily plant production in Ukraine during 1990-2011 (thousand ton)

Such plants as soy, camelina, etc. are still not cultivated in industrial scales. However, compared to Ukraine, only rape oil is considered to be used as a feedstock for biofuel production (Fig. 4.8).

\subsubsection{Review of the Main Oily Plant Potential for Biofuel Production in Ukraine}

Sunflower is the main oily plant cultivated in Ukraine. Its part in total yield is about $70 \%$. Seeds of ordinary breeds contain $50-52 \%$ of oil, while selected breeds contain up to $60 \%$. Compared to other oily plants, sunflower allows production of quite a high volume of oil - 9521 per ha $(890-1$ per ha on average in Ukraine). The last 


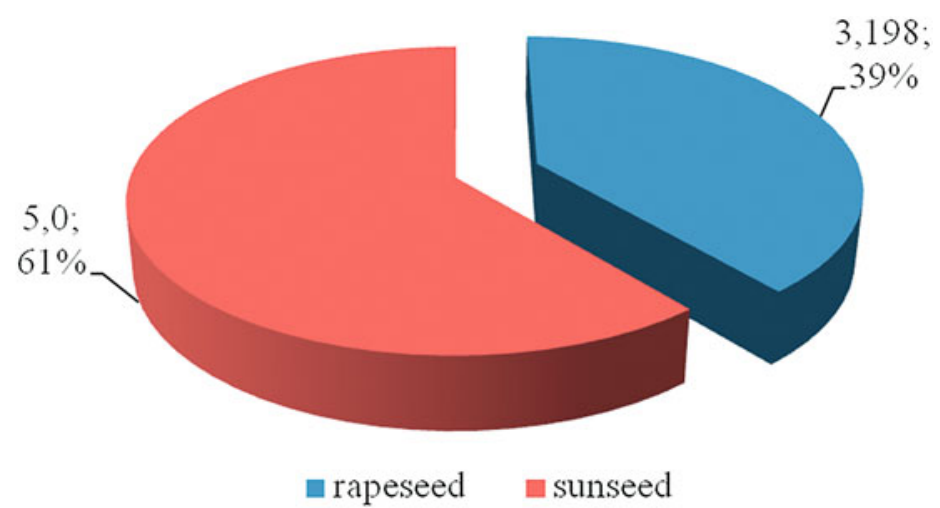

Fig. 4.7 Production of main oily plants in Poland in 2014 (thousand ton)

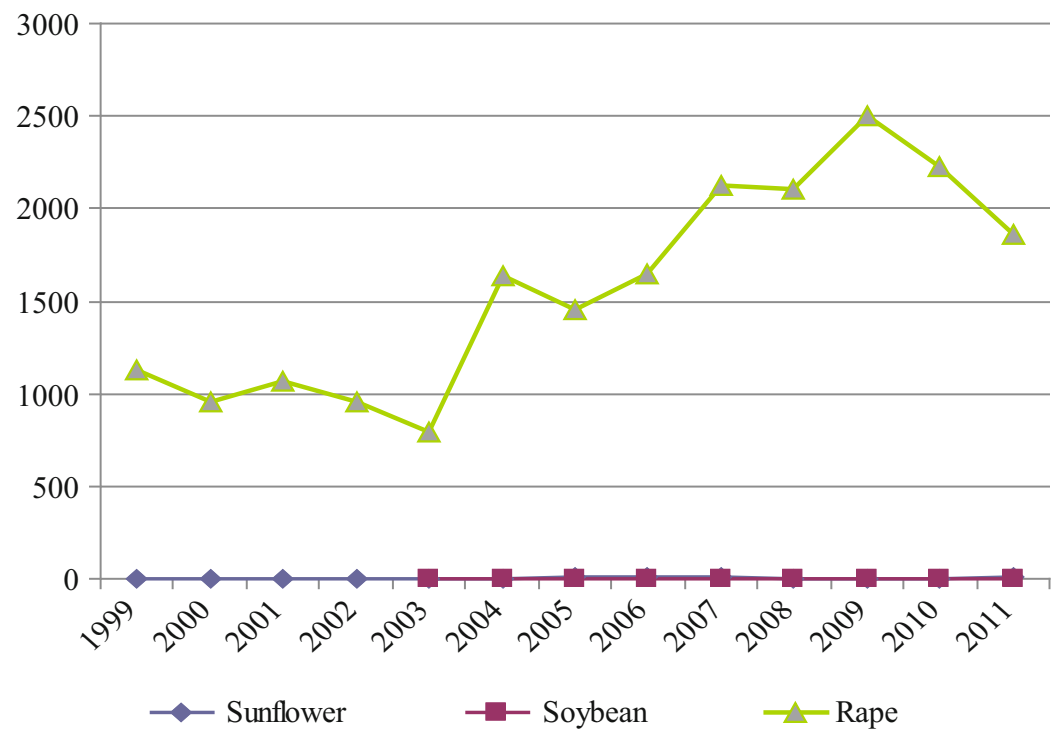

Fig. 4.8 Dynamics of main oily plant production in Poland during 1990-2011 (thousand ton)

years are characterized by significant growth of sunflower production [18]. Today sunflower fertility is about $1840 \mathrm{~kg}$ per ha that is much higher compared to years 2002-2004 (about 1100-1300 kg per ha) (Fig. 4.9). The main part of sunflower is used in the food industry and in the production of high-protein forage, oil meal, and other technical needs. A significant amount is exported that makes a valuable income for the country. Despite so huge production volumes, it is not rational to consider sunflower as a feedstock for biofuel industry, mainly manufacturing of jet biofuel. 


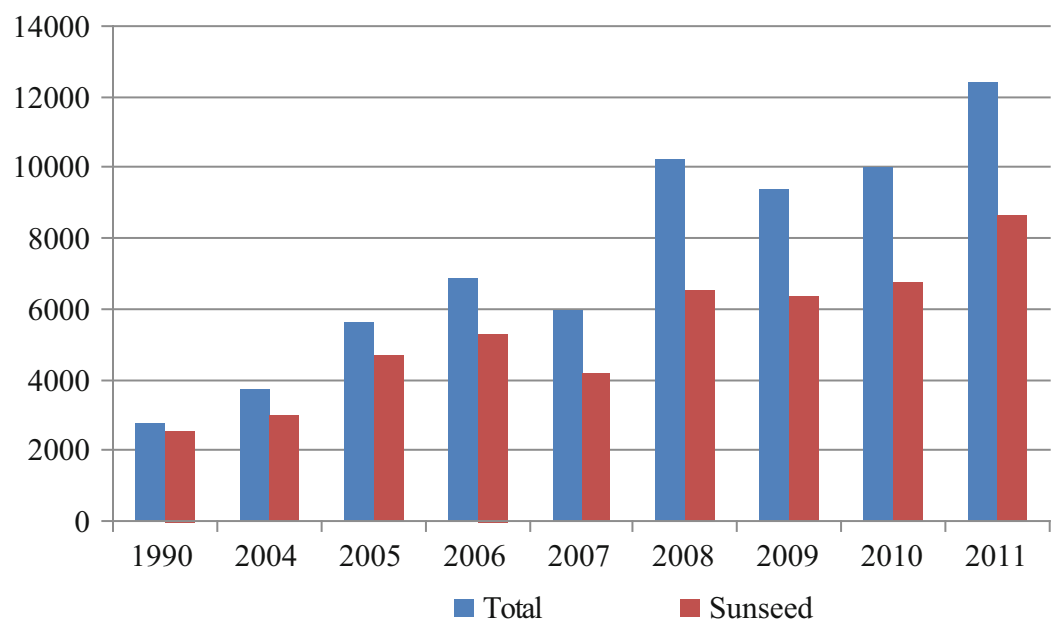

Fig. 4.9 Dynamics of sunflower production in Ukraine and its share in total volume of oily plant cultivation during 1990-2004 (thousand ton)

Another oily plant - rapeseed - is being cultivated in Ukraine in industrial volumes only during the last $8-10$ years. It is explained by strong world demand on rapeseed oil for biofuel production. The most active rapeseed production in Ukraine was observed during years 2004-2008. Rapeseeds contain 45-50\% of oil, $24-31 \%$ of proteins, and 6-12\% of fiber. According to [4], today fertility of rape is about $1500-1700 \mathrm{~kg}$ per ha and can reach up to $2400 \mathrm{~kg}$ per ha. Average yield of rapeseed oil is around $1190 \mathrm{l}$ per ha. Certain rapeseed breeds with low content of erucic acid have been already selected that influence positively biofuel properties. Compared to sunflower oil, rape oil doesn't need preparatory purification from various related components. That is why it is considered to be more appropriate for biofuel production. Several years ago rapeseed was cultivated in Ukraine with the aim of export only. Its internal processing was almost absent and didn't exceed $10 \%$. However, now a significant increase in volumes of internal processing is observed (Fig. 4.10).

Another popular oil culture in Ukraine is soy. Compared to rapeseed, during the recent years, high rates of soy production are observed in Ukraine (Fig. 4.11). Soy average fertility is about $1500-2000 \mathrm{~kg}$ per ha with comparatively low oil yield - 4461 per ha $[4,18]$. The content of oil in soy seeds is about 16-27\%. Soy oil is characterized by high content of unsaturated fatty acids (86-87\%); this makes a certain impact on its physical-chemical properties. At the same time, it contains $40-50 \%$ of high-quality proteins [12]. Due to this soy culture is widely used for production of food oil, protein concentrates, and various food products. These factors made it irrational for biofuel production. It should be mentioned that soy production requires significant resources and material-technical base for its cultivation. 


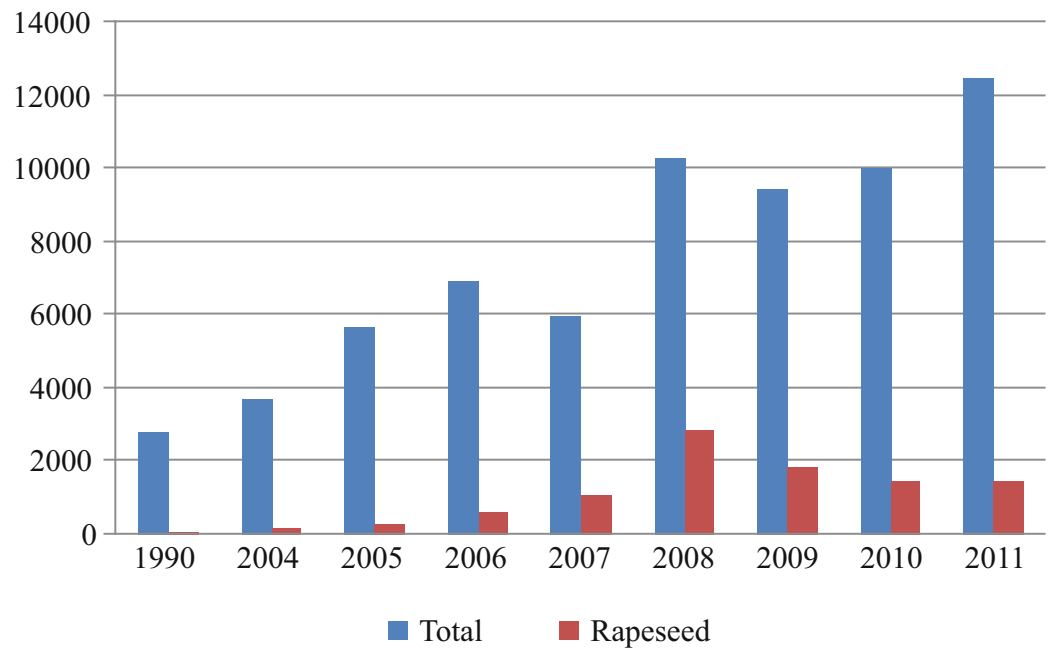

Fig. 4.10 Dynamics of rapeseed production in Ukraine and its share in total volume of oily plant cultivation during 1990-2011 (thousand ton)

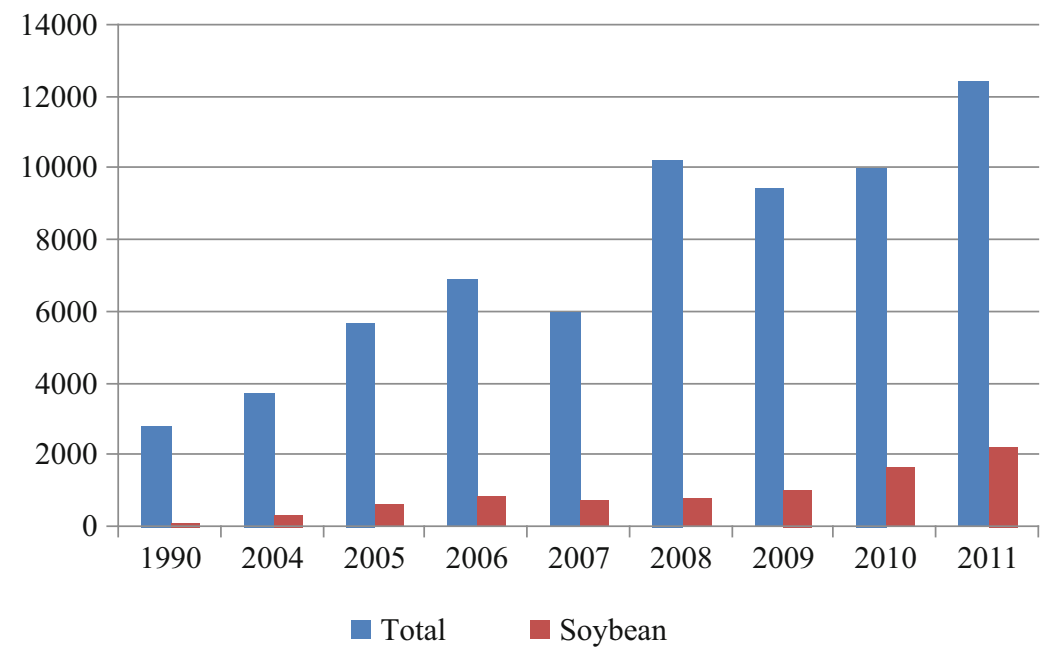

Fig. 4.11 Dynamics of soy production in Ukraine and its share in total volume of oily plant cultivation during 1990-2011 (thousand ton)

\subsubsection{Review of the Main Oily Plant Potential for Biofuel Production in Poland}

During the last years, Poland has become one of the leading countries within the EU, with regard to biofuel production. Having an area of 18.3 million ha devoted to agricultural production, Poland presents great biomass opportunities in energy crop 


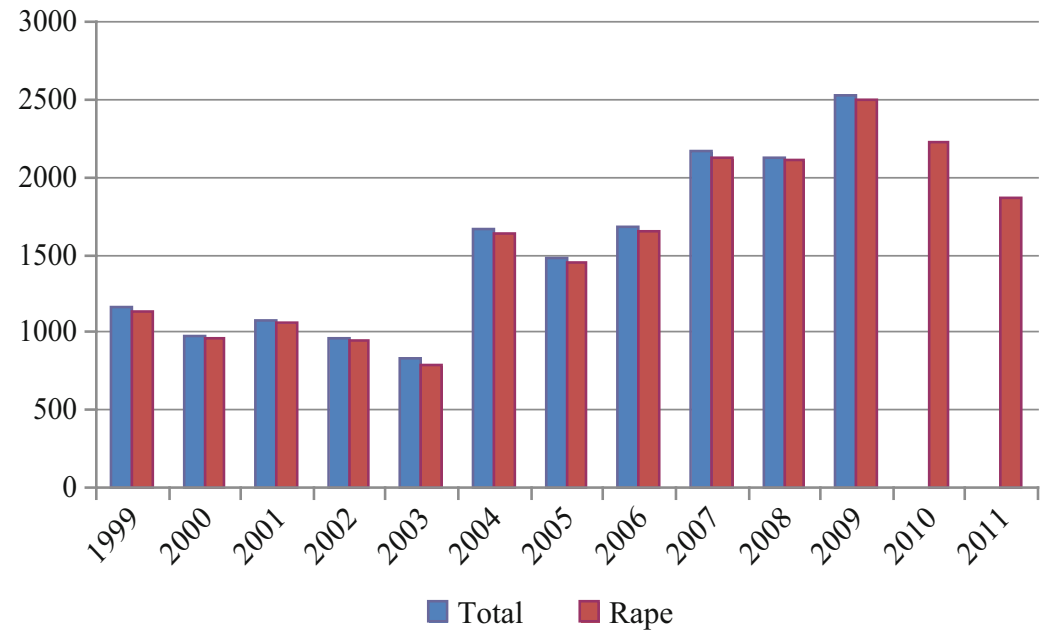

Fig. 4.12 Dynamics of rapeseed production in Poland and its share in total volume of oily plant cultivation during 1999-2011 (thousand ton)

production. Today Poland is treated as one of the main rapeseed-producing countries [23] (Fig. 4.12). As a result, the new capacities in the country are being installed, mainly encouraged by the incipient growth of domestic consumption.

The biofuel sector in Poland is mainly driven by the European incentives and directives aiming at considerably increasing biofuel production and use. Along with other European states according to recent European regulations, the mandatory target for 2020 has been set at a minimum level of $10 \%$ biofuel component in transportation fuels in Poland. Considering the Poland case, the potential of rape cultivation should be determined. More specifically, in Poland, the production of rapeseed increased sharply from 0.7 in 2003 to $1.25 \mathrm{M}$ tons in 2004 [17]. In recent years an increasing trend in biofuel production and consumption can be seen (Fig. 4.13). In 2011, in Poland there were registered 20 producers of biofuels made of rape oil [13].

However, from the graph below (Fig. 4.14), it may be easily seen that volumes of rape production in Poland are generally higher than in Ukraine. It may be explained by the presence of high level of governmental support to biofuel-producing industry. This support is regulated and based on European biofuel implementation programs.

\subsubsection{Review of Camelina sativa Potential for Second-Generation Biofuel Production}

A popular plant for the production of the second-generation biofuels is Camelina sativa. It is an oleifera annual grass. The genus of Camelina includes ten species, which are grown in Europe and Asia in the areas of cool climate of the steppe 


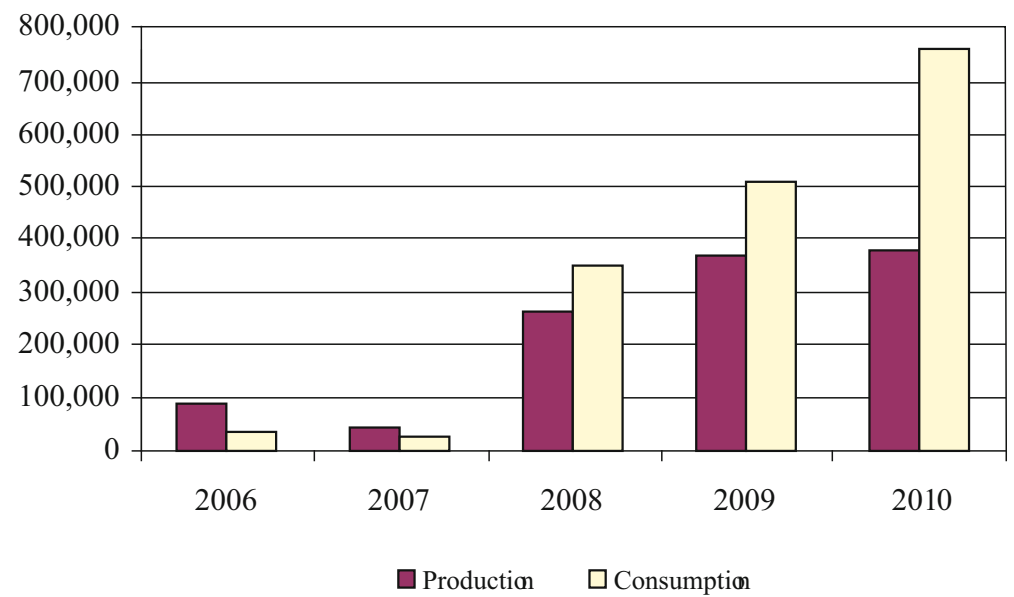

Fig. 4.13 Production and consumption of rape oil-derived biofuels in Poland [13]

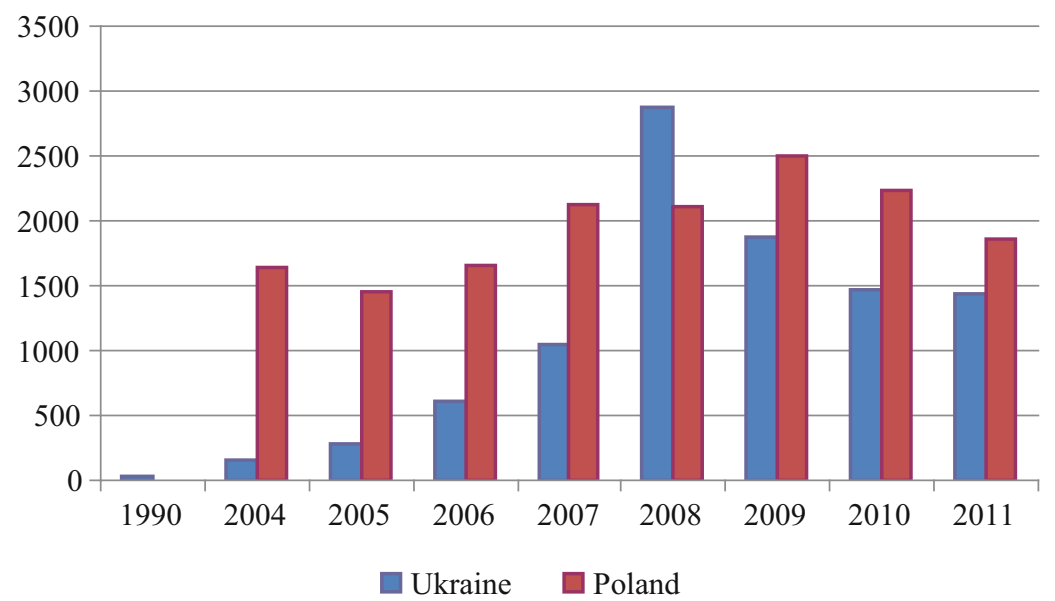

Fig. 4.14 Dynamics of rape production in Poland and in Ukraine (thousand ton)

and forest areas. It can be grown on the fields and fallow lands and along roads. Camelina sativa comes from the countries of Asia Minor, where it was cultivated for centuries. In the second half of the nineteenth century, Camelina was firstly cultivated in Russia and France. In the 1940s-1950s, about 400 ha of the former Soviet Union was covered with Camelina culture. Camelina oil was used primarily in the aerospace industry [20]. Nowadays interest to camelina oil is explained by its potential for use as biofuel feedstock in Europe and the United States. Today camelina is cultivated on some territories of Northwest and Central Europe and not for a long time in Ukraine. Camelina is easily grown on unfertile soils, undemanding to external conditions and resistible to low temperatures and dry weather. It can be 


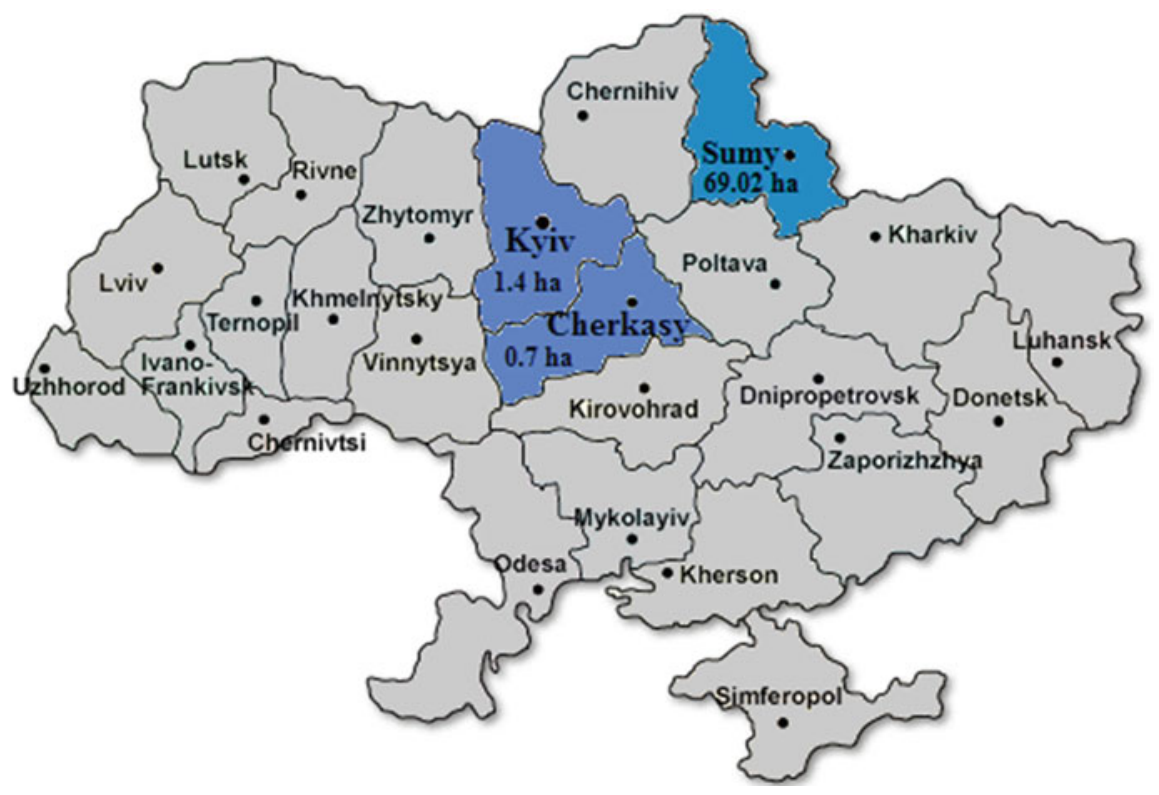

Fig. 4.15 Ukrainian regions where camelina is cultivated [4]

sown when the soil resting from wheat and other grains as part of a crop rotation. Plant has short vegetating period; this allows growing other cultures after harvesting camelina. When it grows naturally its yield is $1000-1200 \mathrm{~kg}$ per ha on average and can reach 2000 and even $3000 \mathrm{~kg}$ per ha. Camelina seeds contain 40-50\% of oil, and oil yield is about $1250 \mathrm{l}$ per ha [16]. During recent years application of camelina oil as a feedstock for biofuel production is highly popular [15].

In Ukraine camelina oil production is still developing. During several decades camelina was cultivated in Ukraine as agricultural crop of secondary importance. Due to the increase in the area under sunflower, rapeseed, and other crop cultivation, camelina was almost expelled. Only small areas are being used continuously for growing up camelina to manufacture soaps and cosmetics, as well as a component of birdseed. Nowadays within Ukraine Camelina culture is grown on small areas in the Polissia region and in the northern forest steppe (Fig. 4.15), although there are prerequisites for the expansion of the areas under this crop. This culture is technical, so biofuel production will not compete with food industry.

In Poland camelina is still not considered as a biofuel feedstock. Taking into account world and European tendencies in particular, we may predict that camelina production in Poland and Ukraine will be increasing rapidly [11, 18]. Camelina is grown in Poland in regions of Podlasie, Wielkopolsce, and Opolszczynys (Fig. 4.16).

If to speak in general, Camelina sativa practically isn't cultivated in Ukraine [9, 10]. It can be easily seen from the diagram (Fig. 4.17) that describes areas taken for the cultivation of Camelina sativa and rapeseed during the period of 2005- 


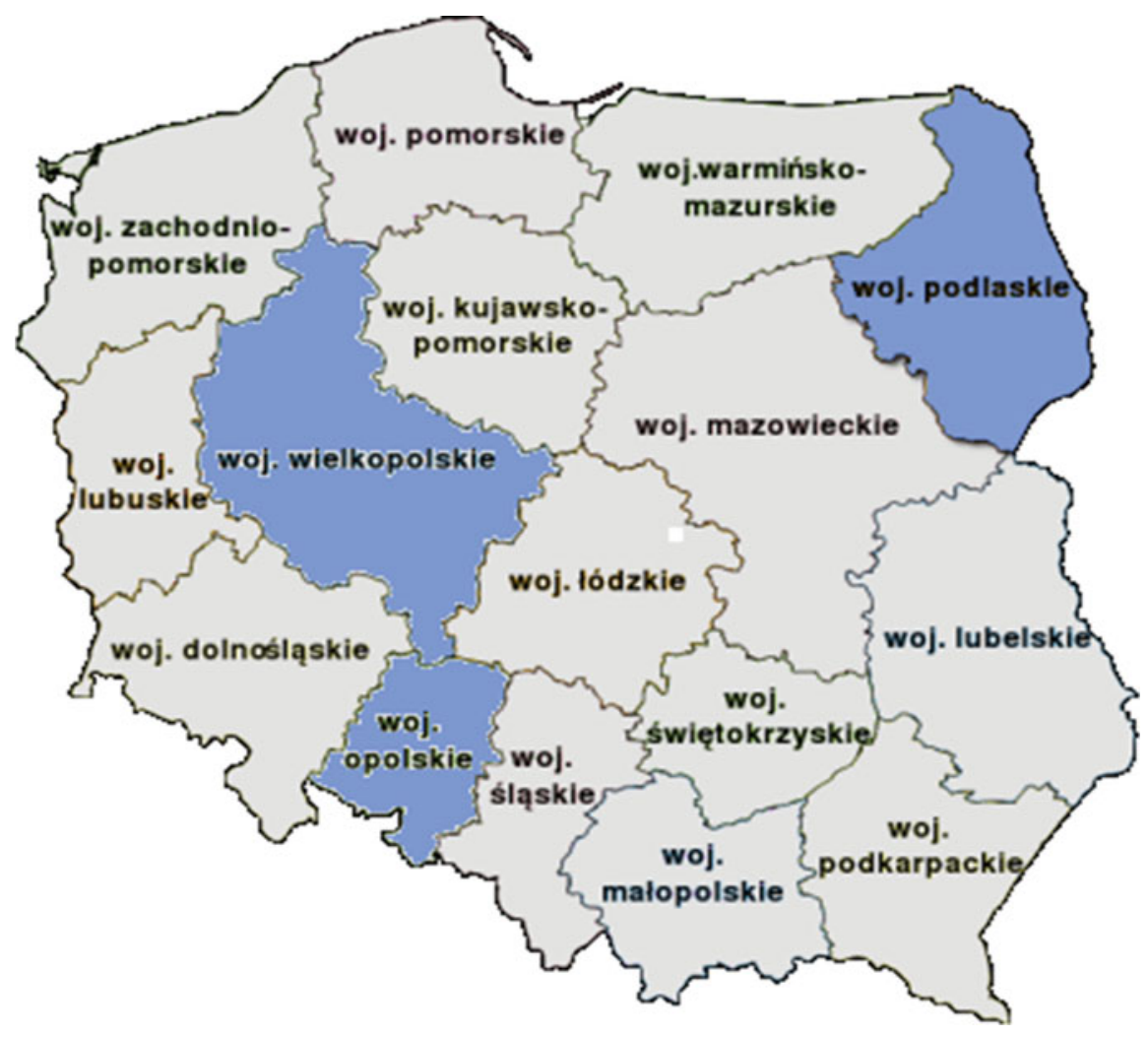

Fig. 4.16 Polish regions where camelina is cultivated [13]

2015. However, taking into account requirements of leading world organizations concerning the sustainability of biofuels, Camelina sativa seemed to be a potential alternative crop which may replace rapeseed in the nearest future.

In order to understand the general characteristics of both biofuel crops camelina and rapeseed, let's compare these crops from the point of view of agriculture (Table 4.1) [19].

As you can see from Table 4.1, Camelina sativa has a larger potential compared with rape that is closely connected with its stability in unfavorable soil and climate conditions. As a result it makes it possible to grow it up in soil of bad quality which is not good for other crops, and it means that we have a chance to get vegetable oil good for producing biofuel without reducing the production of food. Besides, it gives us a real chance to develop agricultural areas with low-quality soils [24]. Scientific research work devoted to technological methods of growing up Camelina sativa and increasing its seed productivity taking into consideration soil and climate conditions in Ukraine, paying special attention to the determination of optimal thickness and regulation of the optimal terms of sowing it, has been done, 


\section{Comparison of areas cultivated with rape and Camelina Sativa in Ukraine, ths hectare}

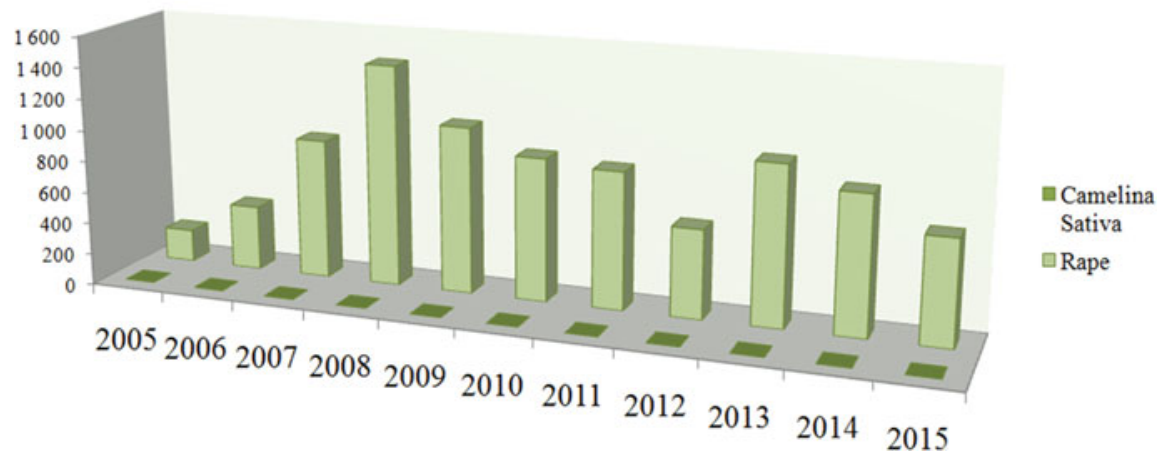

Fig. 4.17 Areas cultivated with Camelina sativa and rapeseed in Ukraine during 2005-2015

Table 4.1 The comparative characteristics of rapeseed and Camelina sativa cultures

\begin{tabular}{l|l|l}
\hline Characteristics & Camelina sativa & Rapeseed \\
\hline $\begin{array}{l}\text { General } \\
\text { characteristic }\end{array}$ & Annual crop & Annual forage crop \\
\hline Drought resistance & Low water demand & Moisture-loving crop \\
\hline $\begin{array}{l}\text { Potential of } \\
\text { germination }\end{array}$ & All types of soil are good & Highly demanding to soil \\
$\begin{array}{l}\text { Threat of soil } \\
\text { fertility decreasing }\end{array}$ & $\begin{array}{l}\text { It is often cultivated along with dead } \\
\text { crops and is used as an intermediating } \\
\text { crop; after harvesting it's possible to } \\
\text { cultivate some other crops }\end{array}$ & $\begin{array}{l}\text { Emaciate soil, it's possible } \\
\text { to cultivate again rape on } \\
\text { the same area only in } \\
3-4 \text { years }\end{array}$ \\
\hline Fertilizers & Are not needed & $\begin{array}{l}\text { Nitrogen-containing } \\
\text { fertilizer is necessary }\end{array}$ \\
\hline Presence of weeds & $\begin{array}{l}\text { It produces ethereal oil which puts down } \\
\text { growth and evolution of weeds from the } \\
\text { phase of stalk formation to full ripe seeds }\end{array}$ & A lot of weeds \\
\hline $\begin{array}{l}\text { The period of } \\
\text { vegetation }\end{array}$ & $\begin{array}{l}60-75 \text { days from the moment when crops } \\
\text { are already standing }\end{array}$ & 90-100 days and nights \\
\hline Loss of seeds & High firmness of pods from chapping & $\begin{array}{l}\text { Low firmness of pods from } \\
\text { chapping }\end{array}$ \\
\hline $\begin{array}{l}\text { Vulnerability of } \\
\text { crops to vermin }\end{array}$ & Vermin and diseases are not found & Badly damaged by vermin \\
\hline
\end{tabular}

and standards of mineral fertilization have been chosen. In addition, growing up the seeds of Camelina sativa and sorghum is ecologically safe because both cultures are characterized as extremely conditions of growing up; they don't need any fertilizers, pesticide and fungicide. 


\subsection{Technology of Jet Biofuel Production}

Oils derived from the abovementioned plants have different physical-chemical properties; however, these differences are not significant. At the same time they differ from properties of fuels for air-jet engines. That is why it is rational to use products of oil processing - ethyl and methyl ethers. Due to chemical composition, biofuel is characterized by high lubricating properties; this allows increasing aircraft detail lifespan. Moreover, application of biofuel produced according to the mentioned technology doesn't require additional reequipment or modernization of engines and their systems. Exclusively low sulfur content in biofuels due to its natural origin may allow significant decrease of toxicity of aircraft exhaust gasses, thus minimizing negative impact on environment. Another quite important factor that determines interest to jet biofuels is its ability to be decomposed easily in natural environment without doing harm to living objects [9].

Considering the suitability of various oils for biofuel production, it is necessary to analyze fatty acid composition of oils (Table 4.2) [14]. It is a well-known fact that fatty acid composition of oils determines physical-chemical properties of oils and thus biofuels. The degree of unsaturation (amount of acids with single or multiple double bonds) determines chemical stability of oil. Under chemical stability we assume resistance of fatty acids to oxidation under various factors, i.e. temperature, light, presence of other compounds, long-term storage, etc. In general, the higher the content of unsaturated fatty acids, the less chemical stability. At the same time the degree of unsaturation influences such important properties as viscosity and melting (or cloud) point of oils. In this case the higher the content of unsaturated fatty acids, the less viscosity and better low-temperature properties. Usually it may be explained by the curved form of unsaturated fatty acids and less compact mutual displacement [5].

From the Table 4.3 we may see that both studied plant oils are reach in unsaturated fatty acids. Camelina oil contains high proportion of linoleic acid (with two double bonds) with considerable content of oleic (one double bond) but lower content of palmitic (no double bonds) acid. The analysis shows that camelina oil contains high amounts of linolenic (three double bonds) acid and eicosenoic acid

Table 4.2 Average fatty acid composition of rapeseed and camelina oils

\begin{tabular}{l|l|l}
\hline \multirow{2}{*}{ Fatty acid } & \multicolumn{2}{|l}{ Plant oil } \\
\cline { 2 - 3 } & Camelina oil & Rape oil \\
\hline Myristic acid & - & $0-1.5$ \\
\hline Palmitic acid & $5.0-6.3$ & $1.0-4.7$ \\
\hline Stearic acid & $2.5-3.0$ & $1.0-3.5$ \\
\hline Oleic acid & $14.5-16.0$ & $13-38$ \\
\hline Linoleic acid & $15.0-17.0$ & $9.5-22$ \\
\hline Linolenic acid & $36.0-38$ & $1-10$ \\
\hline Erucic acid & $1-4,0$ & $40-64$ \\
\hline Eicosenoic acid & $14.8-16.2$ & $0.3-1.0$ \\
\hline
\end{tabular}


Table 4.3 Comparative analysis of properties of oils and esters of rapeseed and camelina oils

\begin{tabular}{|c|c|c|c|c|}
\hline Characteristics & Camelina oil & $\begin{array}{l}\text { Methyl ethers of } \\
\text { camelina oil }\end{array}$ & Rapeseed oil & $\begin{array}{l}\text { Methyl ethers of } \\
\text { rapeseed oil }\end{array}$ \\
\hline $\begin{array}{l}\text { Density at } \\
t=20^{\circ} \mathrm{C}, \mathrm{kg} / \mathrm{m}^{3}\end{array}$ & 923 & 885 & 920 & 880 \\
\hline $\begin{array}{l}\text { Kinematic } \\
\text { viscosity at } \\
t=20^{\circ} \mathrm{C}, \mathrm{mm}^{2} / \mathrm{s}\end{array}$ & 80 & 5,18 & 76 & $6,9-8,2$ \\
\hline Cetane number & 39 & 55 & 34 & $49-56$ \\
\hline Flash point, ${ }^{\circ} \mathrm{C}$ & 250 & 180 & 285 & 170 \\
\hline $\begin{array}{l}\text { Freezing point, } \\
{ }^{\circ} \mathrm{C}\end{array}$ & -18 & -5 & 10 & -7 \\
\hline Heat value $\mathrm{kJ} / \mathrm{kg}$ & 37,400 & 37,000 & 37,400 & $37,000-39,000$ \\
\hline
\end{tabular}

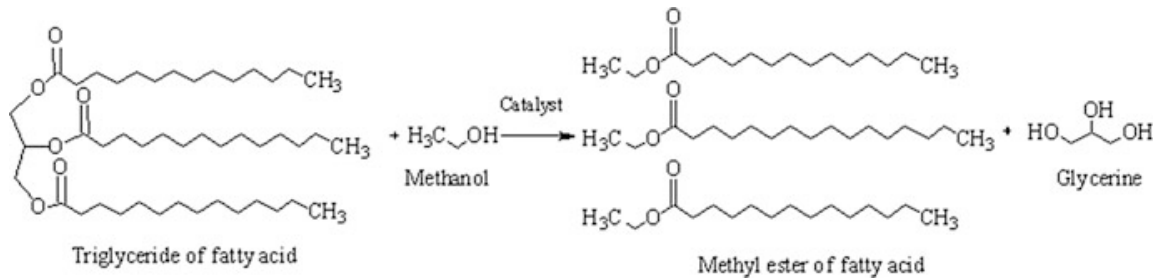

Fig. 4.18 Chemical reaction of plant oil esterification

that has the longest carbon chain. The typical characteristic of rapeseed oil is high content of erucic acid - long-chain acid with one double bond.

Thus, the fatty acid composition of oils determines their physical and chemical properties (Table 4.3). Camelina oil possesses slightly higher viscosity compared to rapeseed oil similarly to density values. It means that the energy value of camelina oil is comparatively higher than rapeseed oil.

The technology of ethyl (methyl) ethers production is quite simple and similar to the process of biodiesel manufacturing. The process is based on the reaction of esterification of fatty acids containing in plant oils using methanol or ethanol and basic catalyst (Fig. 4.18). In a result of this process, esters of plant oil and glycerine are obtained [21]. After that esters of fatty acids undergo the process of vacuum distillation. Vacuum distillation provides a better level of ester purification [10]. This allows using them as components of jet fuels.

The comparative analysis of physical-chemical characteristics of Camelina sativa and rapeseed oils can demonstrate which of the mentioned crops are more suitable for producing biofuels (Table 4.3). For the beginning we introduced some basic physical-chemical parameters of oil and biocomponents made of oils (Table 4.3).

Significant differences in physical-chemical properties of camelina and rapeseed oils, and thus its esters, could be explained by quantitative composition of fatty acids of oils that is presented on the diagram (Fig. 4.19) [19]. 


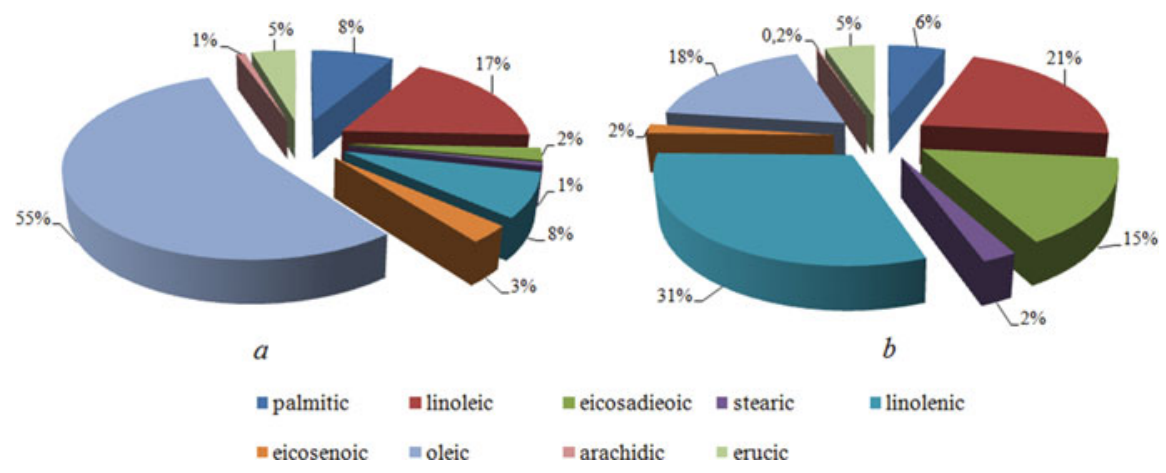

Fig. 4.19 Composition of fatty acids of (a) rapeseed and (b) camelina oils, \%

In order to conclude, camelina oil raises interest as a potential raw material for the production of aviation fuel components (biofuel of the second generation). The increase of area cultivated with Camelina sativa allows to resolve range of issues.

Social issue: in contrast to rapeseed, crop cultivation of Camelina sativa does not require utilization of rich soils which could be occupied by food crops.

Agricultural issue: Camelina sativa could be easily grown in poor soils and does not require usage of pesticides and fungicides.

Environmental issue: usage of plant-based fuel components decreases volume of emission of greenhouse gas. For Ukraine this becomes especially important considering its scarce energy resources that could be used for aviation fuel production, while at the same time, the country possesses a significant area of agriculture lands. Additionally it is worth mentioning that the existing potential in the area of biofuel production is not realized in Ukraine due to the absence of modern production facilities.

Today the technology of biofuel production is realized successfully both in laboratories and industrial enterprises. Taking into account experiences of European countries, biofuel manufacturing in Ukraine can be organized at the lowtonnage installations (local level for certain enterprises) with productivity 300 3000 ton/year, regional factories, producing 10,000-30,000 ton/year, and large-scale industrial factories [8]. Technological process of jet biofuel production from plant oils is significantly simpler compared to crude oil refining and profitability of the process in two to three times higher. Except that, plant feedstock is a renewable resource, and thus it is comparatively unlimited. 


\subsection{Conclusion}

In general Ukraine and Poland among other countries have considerable resource potential for jet biofuel production from plant oils. The main advantage of feedstock cultivation in Poland is the presence of high level of governmental support to biofuel-producing industry that is based on European biofuel implementation programs. However, Poland's potential in biofuel feedstock production is not realized completely. Today only rapeseed is cultivated for providing feedstock for biofuel production; at the same time, the biofuel potential of sunflower, soy, or camelina oils is not realized. On the contrary with no or almost absent governmental support, Ukrainian producers develop oil production from traditional oily plants for satisfying biofuel industry needs. Being one of the leading countries in Europe by volumes of rape and sunflower production, Ukraine is still one of the top rapeseed exporters to the EU. At the same time, Ukrainian oil producers promote growing of new biofuel cultures, such as camelina, soy, and some others. These countries have all possibilities for jet biofuel manufacturing for satisfaction of its own needs and for export also.

Implementation of biofuels derived from plant feedstock surely has potential and perspective for its future development. Application of biofuels should totally be the scope of sustainable development principles and doesn't do harm to food industry. In the future application of alternative jet fuels will have the following positive results: availability of feedstock that is important for countries, which don't possess its own deposits of fossil fuels; saving of exhaustible energy resources; decreasing volumes and toxicity of aircraft exhaust gasses, thus protecting air quality in lower atmosphere layers; comparative simplicity and low cost of biofuel production process; low price for biofuel compared to traditional kerosene; and stimulation of agricultural complex development in countries-producers of biofuels.

In general Ukraine and Poland have considerable resource potential for jet biofuel production from plant oils due to its favorable natural climatic conditions, availability of feedstock base, and relatively cheap human resources.

The main advantage of feedstock cultivation in Poland is the presence of high level of governmental support to biofuel-producing industry. However, Poland's potential in biofuel feedstock production may be increased due to sunflower, soy, or camelina oil production.

The opposite situation is observed now in Ukraine. With no or almost absent governmental support, Ukrainian producers develop oil production from traditional oily plants for satisfying biofuel industry needs.

At the same time Ukrainian oil producers promote growing of new biofuel cultures, such as camelina, soy, and some others. If to speak in general, these countries have all possibilities for jet biofuel manufacturing for satisfaction of its own needs and for export also. 


\section{References}

1. Bauen, A., Howes, J., Bertuccioli, L., et al. (2009). Review of the potential for biofuels in aviation. [online] Biofuels in aviation E4tech Final report (for CCC), available via http://citeseerx.ist.psu.edu/viewdoc/download;jsessionid=E296A64BF3E834001 B8281496DA49C7D?doi=10.1.1.170.8750\&rep=rep1\&type=pdf. Accessed 13 Jan 2014.

2. Boichenko, S., \& Zakharchuk, M. (2012). Aviation fuels and lubricants. Kyiv: NAU.

3. Devianin, S., Markov, V., \& Semenov, V. (2007). Plant oil and fuels for diesel engines. Kharkov: Novoe Slovo.

4. Dubel, A. (2010). Peculiarities and economic efficiency of rape cultivation. Innovative Economics, 2, 88-91.

5. Giakoumis, E. (2013). A statistical investigation of biodiesel physical and chemical properties, and their correlation with the degree of unsaturation. Renewable Energy, 50, 858-878.

6. Hemighaus, G., Boval, T., Bosley, C., et al. (2006). Alternative jet fuels. Addendum 1 to Aviation Fuels Technical Review Chevron Corporation, FTR-3/A1.

7. Iakovlieva, A., \& Boichenko, S. (2012a). Cause-effect analysis of jet fuel production and state of environment. Systems and Means of Motor Transport, 3, 239-246.

8. Iakovlieva, A., \& Boichenko, S. (2012b). Application of biokerosene for improvement of jet engines' ecological characteristics. Aviation and Cosmic Technics and Technology, 7(94), 6064.

9. Iakovlieva, A., Boichenko, S., \& Vovk, O. (2013). Investigation of properties of biocomponents used in mixture fuels for jet engines - chemmotological view. Systems and Means of Motor Transport, 4, 351-356.

10. Iakovlieva, A., Vovk, O., Lejda, K., et al. (2014). Improvement of technological scheme of fatty acids ethyl esters production for use as jet fuels biocomponents. International Journal of Theoretical and Applied Science, 11(19), 44-50. DOI: http://dx.doi.org/10.15863/ TAS.2014.11.19.9.

11. Kaletnik, G. (2008). Economic efficiency of biofuel market development in Ukraine. Problems of Science, 12, 38-43.

12. Kondili, E., \& Kaldellis, J. (2007). Biofuel implementation in East Europe: Current status and future prospects. Renewable and Sustainable Energy Reviews, 11, 2137-2151.

13. Królczyk, J., Latawiec, A., \& Kuboń, M. (2014). Sustainable agriculture - the potential to increase wheat and rapeseed yields in Poland. Polish Journal of Environmental Studies, 3, 663-672.

14. Kumar, V., \& Kant, P. (2013). Study of physical and chemical properties of biodiesel from sorghum oil. Research Journal of Chemical Sciences, 9, 64-68.

15. Nikolaeva, N., Stepycheva, N., \& Kozlov, V. (2005). Change of physical-chemical properties of rapessed oil depending on term of their cultivation. Chemistry of Plant Feedstock, 2, 32-34.

16. Petcu, A., Carlanescu, R., \& Berbente, C. (2014). Straight and blended Camelina oil properties. Recent Advances in Mechanical Engineering, 4, 160-167.

17. Pietak, A., \& Radkowski, S. (2011). Biofuels - opportunities and challenges. Journal of KONES Powertrain and Transport, 3, 25-31.

18. Proskurina, O. (2011). Perspectives of production and application of biofuel in Ukraine. Theoretical and practical aspects of Economics and Intellectual Property, 1, 12-15.

19. Prahova, T. (2013). Camellina: Biology, productivity, technology. Proceedings of Altai State Agrarian University, 9(107), 24-28.

20. Rachmetov, D., Blume, Y., Yemets, A., et al. (2014). Camellina sativa - precious oil feedstock. Institute of Food Biotechnology and Genomics, 2, 16-21.

21. Sagar, P., Kadu, R., \& Sarda, H. (2011). Use of vegetable oils by transetherification method as C.I. Engine fuels: A technical review. Journal of Engineering Research and Studies, 2(3), 19-26.

22. Walker, D. (2009). Biofuels, facts, fantasy, and feasibility. Journal of Applied Phycology, 21, 509-517. 
4 Case Study of Alternative Jet Fuel Production with Bio-additives from Plant. . .

23. Wisniewski, G., Kupczyk, A., Rogulska, M., et al. (2005). Development of biofuels market in Poland. Proceedings of the International Conference International Conference 'Eastern Biofuels', 4, 176-184.

24. Zelenina, O., \& Prahova, T. (2009). Fatty acids composition of camellina oil seeds. Oily Cultures, 2, 54-57. 